\title{
Augmented Reality System to Promote the Inclusion of Deaf People in Smart Cities
}

\author{
César Lozano Diaz ${ }^{1}$, Rocio Maciel M. ${ }^{1}$, Manuel Larios V. ${ }^{1}$, C. Alberto Ochoa ${ }^{2}$ \\ ${ }^{1}$ University of Guadalajara Smart Cities Innovation Center, Zapopan, Mexico \\ ${ }^{2}$ Universidad Autónoma de Ciudad Juárez, Mexico
}

\{clozano,rmaciel,vmlarios\}@ cucea.udg.mx, alberto.ochoa@uacj.mx

\begin{abstract}
The use of technological tools for the inclusion of people with auditory disabilities today is booming, with a significant advance in the close caption for television, the cochlear implant, dictionaries of sign languages apps (SL) in apps, translators of voice-to-text or channels of videos that promote the learning of SL, but without a visible impact in the communities of deaf people or society in general, is still not perceived this technology being adopted everywhere to promote equal opportunities and the well-being of people with disabilities in the Smart cities, due to many of the developments do not pursue the research, usability analysis or the creation of models that help to understand, replicate, improve, or build strategies to ensure an inclusion based on technology and the immersion to the deaf culture by listeners The systematic review to research conducted in this topic helps us understand the implications and challenges faced To follow with innovation in the area of technologies for inclusion and understand that not only it is providing technology for a deaf person, but to create an environment that promotes culture to improve communication between inhabitants of a Smart cities. For this reason the present article is a systematic revision centered in technological research adapted for the access of the information and the communication of people with hearing loss or deaf; presented under Kitchenham's methodology; the information is searched and classified through the analysis of clusters k-means which summary is presented under the selection and classification of 350 articles published since 2013 until May 2017 with looks towards the analysis of methodologies or models that promote the inclusion of deaf people in society with the usage of technological tools in order to start the guidelines to create a technological-social model to promote the improvement of communication between deaf and hearing people.
\end{abstract}

Keywords: inclusion, augmented reality, translation from voice to text, deaf people. 


\section{Introduction}

The constant evolution of portable devices and emerging technologies have allowed development of applications that promote the inclusion of deaf people, or with hearing loss in school environments and urban environments, all of them developed to promote a better quality life.

Bouzid et al. in [1], affirm as the technologies become smaller and cost reduction, there is a high probability that deaf people have access to school education with the assistance of technology, through the adoption of proper technologies; However, from the perspective of deaf people community this connection is still far away, according to Ruiz [2], the results of his research had confirmed that the social inclusion in the school method still has not been effective at all, the lack of replicable models and the fact the sign language is different in every country had complicated the process; this leads the people interested in the subject to question: Are there sufficient research that allows creating replicable models for the inclusion of deaf people?, Is there sufficient technology to guarantee the access of information to deaf people?, Is it all said in themes of inclusion for deaf people?, and last, Is it appropriate continue develop improvement in existing technologies or create new technologies to promote its inclusion?. Therefore, this systematic revision is looking to provide information that allows studying the possible solutions to these previous questions like a validation for the develop of future research in the matter.

Now it has become indispensable for the future of Smart cities guarantee the access to the information to its population with special needs; improving the accessibility to public places will absolutely determinate the life conditions of the people, the accessibility standards should be comprehensive across all barriers [3], cities were its population will have a higher number of deaf people, according to the OMS [4] exists 360 million people in all around the world with hearing loss, of which 32 million are children, this quantity has been increasing due to genetic causes, complications during labor, infectious diseases, chronic infections in the ear, the usage of some medicines, the exposure to excessive noise to mention some of facts, hence it is necessary completely know where the research is located and the technologies in this matter to continue the development of these technologies guarantying the smart living.

\section{Methodology}

This study was conducted as the systematic revision of literature using proposed directives by Kitchenham [5]. In this case, the objective of this review is to evaluate the research referred to the inclusion of deaf people and technologies developed for them.

The steps in the revision method of systematic literature will be documented as the following: 


\subsection{Research Questions}

Starting from the principal questions of the research, which lead us to consider general questions:

RQ1. Which technologies and infrastructure exists in the cities for the inclusion of deaf people in the different areas of a smart city?

This question is related to the importance on knowing that has been done and is being done with the technology in support of deaf people in the cities, schools or business. To answer this will contribute to analyze if it is still relevant for further research on the topic.

RQ2. Has it been worked with RA as the way to promote in the deaf people community the access to the communication?

Through this analysis examines the relevance of developing applications with augmented reality (AR) for the access to the spoken information and the teaching and learning of language of sign (SL). Due to the fact that in the AR is a technology that allows you to increase the information that an individual can obtain for himself to interact with the physical world, to provide more data than that which cannot be registered through the senses.

RQ3. How will this impact the metrics in the school of a smart city, in the inclusion of deaf people?

The answer to these questions takes relevance in assessing the importance of continue to develop improvement in existing technologies or create new technologies to promote the access of education, work and communication, helping the incorporation into the labor force to the thousands of people who have been excluded from many of these specialized environments, if this occurs, the impact on the economic growth of a smart cities will be benefited.

The analysis of these questions generates the opportunity to separate the variables that allow building the key words used in the first phase, with the purpose of building a search matrix to use a clusters analysis. Table 1.

Table 1. Search terms (The search is done with the keywords and their possible synonyms).

\begin{tabular}{ll} 
Key works & Synonym \\
\hline Inclusive education & Inclusive \\
\hline Augmented reality & AR \\
\hline Virtual reality & VR \\
\hline Translation from Voice to text & Subtitle, translation \\
\hline People deaf & \\
\hline Sign Language & LSM \\
\hline Voice recognition & \\
\hline Inclusion educational model & Model, inclusion \\
\hline Virtual avatar & assistant
\end{tabular}

The methodology selected to analyze the usability of the technology developed is a qualitative type, following the method research-action emancipatory; considering that 
this method is closely compromised with the transformation of the organization and social practice. In which is proposed a critical process of intervention/reflexion, practical, of action and change, of ethic and compromise to the community service.

The analysis of usability, it is done in the University of Guadalajara, between a sample of 4 deaf students, and in the case of the serious game a sample will be done with 100 hearing students in the language center of CUCEA (Economic and Management Sciences).

\section{Search Strategy}

\subsection{Sample Protocol and Registration}

The revision protocol is being performed using the data bases, IEEE, EBSCO, Jstore, Sage Journals, the key words will be used under the criterion:

Word in abstract / just a Journal/ period 2013 - 2017 / language. Based on this, the research matrix will be built. (This one can be viewed in this web page link http://bit.ly/2sqeBI3).

This brings the total of 3,743 relevant and timeless articles in the four data bases mentioned previously. This quantity is high. In advance research, if we cannot make that by searching using key words, it means that the article is centered on this theme. Hence the need of using Cluster analysis, which allows us to find the whole possible homogenous groups, gathered by their probable similarity, by measuring their Euclidean distances. (The distance matrix is constructed using the number of documents found in each database. Distances and iterations are calculated using the SPSS software).

The dendrogram (Figure 1), obtained after having applied the k-means with five interactions, helps create a second search by groups in which they were called:

a) Emerging Technology,

b) Means of communication,

c) Possible means,

d) Education.

Through the K-means iterative partition, the compound groups are examined in each partition to be subdivided and give way to new groups. The decision on the cluster number is represented by the evolution of the mergers. After that, groups are separated to form search chains, reducing the probability of finding duplicate investigations in each database, due to the groups formed. 


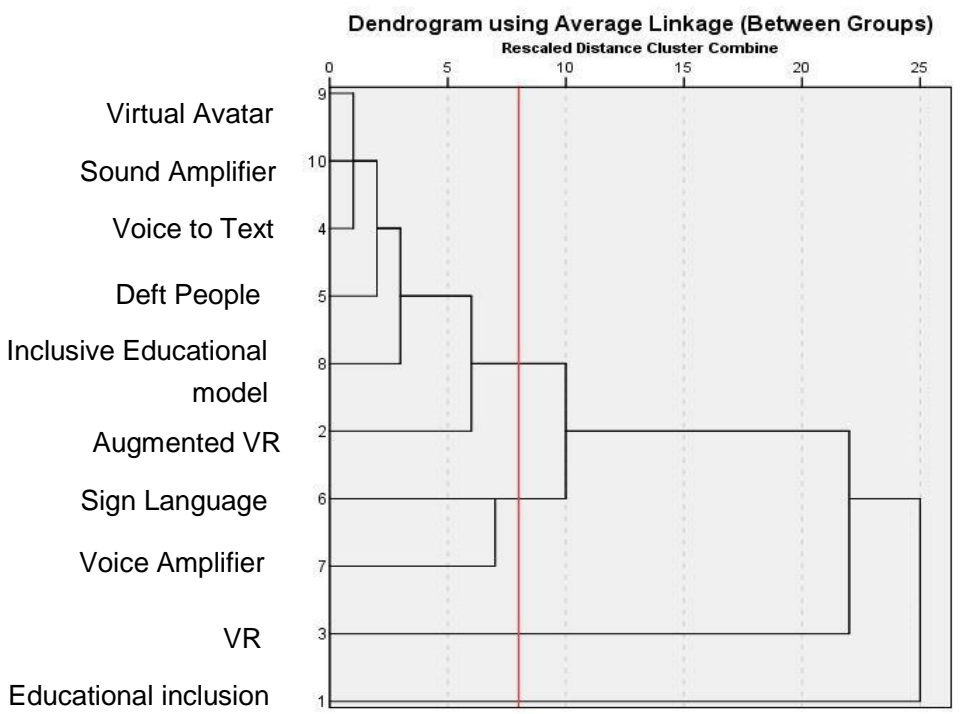

Fig. 1. Dendrogram: Graphical representation of the hierarchical classification, obtained by applying the k-means cluster method in SPSS.

\subsection{Search Strategy}

The criterion for the second search is based on the formed groups, creating search starting with the combination of their terms and logic connecting AND" and "OR". Table 2 .

Table 2. Formed chains based on groups formed in the dendrogram.

\begin{tabular}{cl}
\hline & \multicolumn{1}{c}{ Search chains } \\
\hline \hline 1 & $\begin{array}{l}\text { ((Virtual avatar) OR (Sound amplifier) OR (Translation of voice to text)) AND ((Deaf } \\
\text { people) OR (Deaf)) }\end{array}$ \\
\hline \hline 2 & $\begin{array}{l}\text { ((Virtual avatar) OR (Sound amplifier) OR (Translation of voice to text)) OR (Deaf } \\
\text { people)) AND (Deaf) AND (Inclusive education model) }\end{array}$ \\
\hline \hline 3 & $\begin{array}{l}\text { ((Virtual avatar) OR (Sound amplifier) OR (Translation of voice to text)) OR (Deaf } \\
\text { people) OR (Deaf) OR (Inclusive education model) AND (augmented reality)) }\end{array}$ \\
\hline
\end{tabular}

\subsection{Source Selection}

907 articles are obtained under the chain of search selected in the same data bases and the same criteria: Abstract / just in Journal / period 2013 - 2017 / Language English.

The numbers of articles that belong to each group is the following: a) Emerging technology ten articles b) Means of communication 889 articles, c) Possible means five articles c) Education three articles.

For the selection process, the MacDonnell and Shepperd [6] strategies are applied in which consists in reviewing the titles and summaries to articles found to classify 
them. For those articles that lack information in their summary, their introduction and conclusions were read in order to identify the required information.

\section{Study Selection}

The titles were reviewed, summaries and conclusions of each article found under this pre-selection 350 of 907 articles are distinguished in which 156 articles are preselected, 94 articles were discarded, since technology is not mentioned.

\subsection{Data Collection Process and Data Extraction}

The relevance of the article is considered based on the study field, the technological tools used and the contributions to inclusion model. It is also considered if the article is a case study or a theoretical proposal. Besides, the number of quotes that contain the articles and the impact factor when it was published are taken into account. Figure 2 (In the last two cases they were found using Scholar Google).

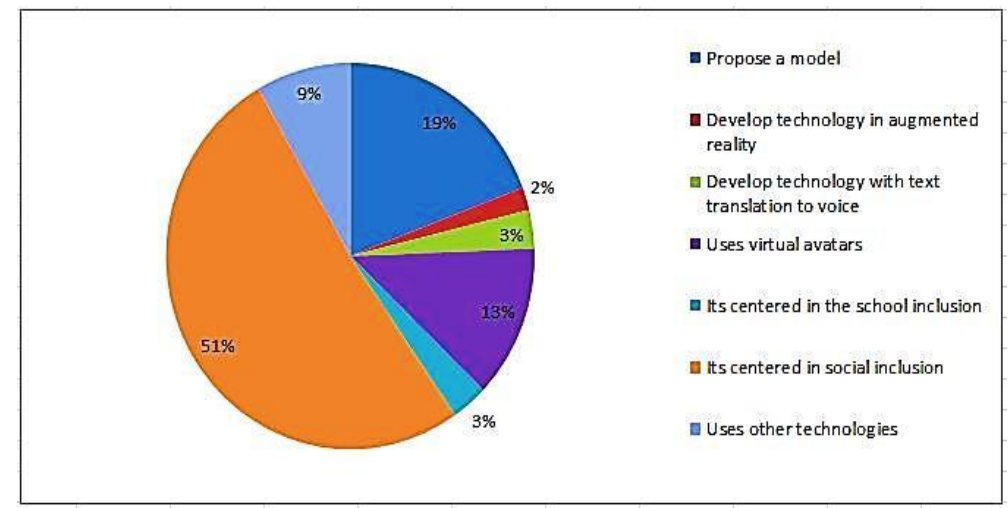

Fig. 2. Percentage of articles

\subsection{Synthesis of Results}

The 156 selected articles in the research themes were presented below: More articles are found centered on social inclusion, corresponding to the 51\%.60/80 were found doing it in case studies, 20/80 of theoretical method approaching the improvements in quality life of people with hearing loss through the existing technology or SL interpreter, only $19 \%$ talk about the creations of models to improve the quality of school education or mobility in the cities, 3/30 talk about models for smart cities and technologies that foster the life quality of their population with disabilities, $3 \%$ have developed technologies with translation from voice to text, $3 / 5$ have made usage of it in pilot tests and $2 / 5$ are already enabled (these include the subtitle in videos). $13 \%$ propose the usage of virtual avatars for the translation of SL, $2 \%$ have used augmented reality to enable usage of this technology for the learning of sign 
language, 3\% are centered on school inclusion through some technologies, $9 \%$ are centered on the usage of other technologies like antennas and cochlear implants.

Table 3. Most relevant technologies and characteristics for the study.

\begin{tabular}{|c|c|c|c|c|c|c|c|c|c|c|}
\hline & \begin{tabular}{|c|} 
Diffused in \\
congress
\end{tabular} & $\begin{array}{l}\text { Diffused in } \\
\text { another } \\
\text { medium }\end{array}$ & Paper & Description & Type & Country & $\begin{array}{c}\text { Proposes } \\
\text { model }\end{array}$ & Available & $\begin{array}{c}\text { company or } \\
\text { institution }\end{array}$ & Language \\
\hline Dilo con señas & Yes & Yes & NO & $\begin{array}{l}\text { LEARNING SIGN } \\
\text { LANGUAGE }\end{array}$ & APP & México & YES & YES & \begin{tabular}{|l|} 
JAGUAR LABS \\
\end{tabular} & SPANISH \\
\hline $\begin{array}{r}\text { Interpreter sign } \\
\text { language for } \\
\text { communication hearing } \\
\text { impaired using image } \\
\text { processing }\end{array}$ & Yes & No & Yes & $\begin{array}{l}\text { SIGN LANGUAGE } \\
\text { TRANSLATOR }\end{array}$ & SOFTWARE & Colombia & No & No & $\begin{array}{l}\text { INSTITUTION } \\
\text { ANTONIO } \\
\text { JOSE } \\
\text { CAMACHO }\end{array}$ & SPANISH \\
\hline $\begin{array}{r}\text { Sign language } \\
\text { recognition and } \\
\text { translation with kinect }\end{array}$ & Yes & Yes & Yes & $\begin{array}{l}\text { SIGN LANGUAGE } \\
\text { TRANSLATOR }\end{array}$ & SOFTWARE & China & NO & NO & $\begin{array}{l}\text { MICROSOFT } \\
\text { RESEARCH } \\
\text { ASIA }\end{array}$ & ENGLISH \\
\hline Hand talk & No & Yes & No & $\begin{array}{l}\text { SIGN LANGUAGE } \\
\text { TRANSLATOR }\end{array}$ & $\begin{array}{l}\text { APP, WEB } \\
\text { PAGE }\end{array}$ & Brasil & YES & YES & $\begin{array}{l}\text { HAND } \\
\text { TALK }\end{array}$ & PORTUGUESE \\
\hline Hablalo & Yes & Yes & No & VOICE TOTEXT & APP & Argentina & YES & YES & $\begin{array}{l}\text { MATEO } \\
\text { SALVATO }\end{array}$ & SPANISH \\
\hline LTCCS & NO & Yes & YES & $\begin{array}{l}\text { SIGNLANGUAGE } \\
\text { TRANSLATOR }\end{array}$ & PROPOSE & India & YES & No & & ENGLISH \\
\hline Microsoft trasnlator & YES & Yes & YES & $\begin{array}{l}\text { VOICE TO TEXT AND } \\
\text { TRANSLATOR }\end{array}$ & $\begin{array}{l}\text { APP. WEB } \\
\text { PAGE }\end{array}$ & USA & NO & YES & MICROSOFT & 66 LANGUAGES \\
\hline Ava & No & Yes & No & VOICE TO TEXT & APP & USA & No & YES & \&AVA & ENGLISH \\
\hline
\end{tabular}

\subsection{Risk of Bias within Studies}

Furthermore, as a second search made in order to decrease the possibilities of publication bias, the bibliographic list of the selected articles in the main search were examined, with the objective of identifying studies not detected in the revision, it should be noted that it is possible that exist technology developed to access the information and communication designed for deaf people but research has not been done about the impact or viability in society which could cause a problem while trying to study the progress of the adapted technologies.

\section{$5 \quad$ Results of Individual Studies}

The existing technologies for the inclusion of deaf people in the different areas of an smart city are analyzed, the following are the most impact: sign language [7], "interpretive sign language for hearing impaired communication through processing images "[8], recognition and translation of sign language with Kinect [9], talk about it, hand talk [10], ava [11], signpost, whose specifications are shown below in Table 3. 


\subsection{Evidence Summary}

The results obtained in this present job, allow demonstrate the existence of scientific literature related to the implementation of technologies that assist the access to communication and information for people with hearing loss disability, defined to promote the interest of research. The analysis of the quality of the articles that were included in this systematic revision had helped to sustain the scale of importance that all the scientific community of each of the studies selected. Although there are not many studies that directly linked the deaf people with the augmented reality to provide accessibility in smart cities specifically, the research work is highlighted done by Mizaei [12] and Nikita [13]. Being this a divided water to link the usage of technology with the simultaneous translation from voice to text.

\subsection{Speech View Application}

The purpose of developing a Speech View application is to have an intuitive UI for users with hearing disability, which provides them access to information in their environment; it is about augmented reality, simultaneous translation from voice to text / text to voice and QR codes, (for reproduction of videos in Mexican sign language LMS, both informative and for the basic learning of this); to be used in work environments, equipment and customer service, typical of an smart city and validated by the user.

Commonly, when a simultaneous translation is made, a person (stenotipista) writes what it is spoken. With help of computers and a projector screen, there is also the alternative of having a sign language interpreter. This is usually used in congresses or mass events. Due to the high costs and the small number of specialists in these issues, other alternatives should be analyzed, such as the one proposed in this research, to promote access to information without depending on an SL interpreter at all times. With the help of the VR application, information can be projected directly from the computer or cell phone.

\section{Description of the Application Service}

The user activates the voice-to-text service, having pre-configured the translation language. Using your phone camera, you can see the environment and expect a person's dialogue to be presented as a subtitle. At any time, the person can activate the text-to-speech option, where the user enters a dialogue via the keypad of the phone or tablet. By pressing the "talk" button, the text will be dictated by a male or female voice, depending on the configuration. These functions require connectivity. The data consumption must be measured in the usability tests to improve the user experience. In case the user does not have internet, an error message must be displayed in connection.

The processing capacity depends on the data and audio quality, so it is recommended to use a stable connection. This service is paid in packages with different costs (so you must attach the option to purchase characters in the menu). 
The application is programmed in UNITY using C\# and the APIS by IBM Blumix WATSON Figure 4, which have three main functions:

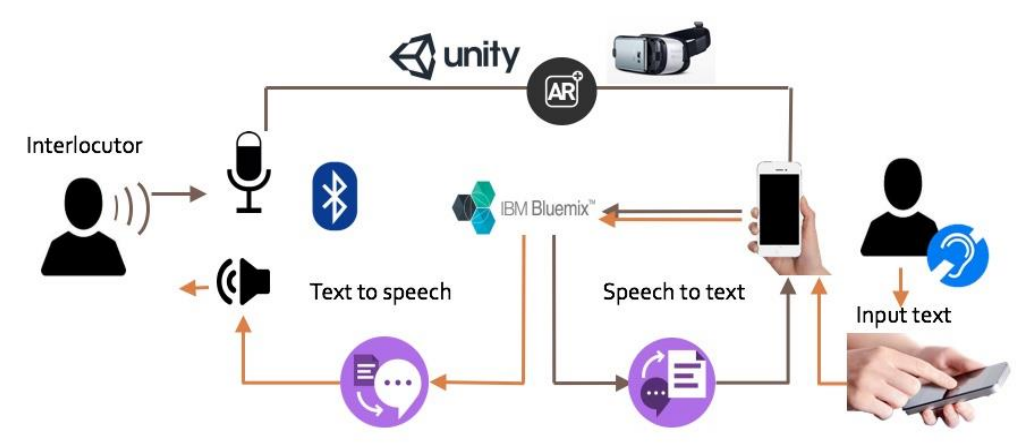

Fig. 3. The translation from voice to text using the APIS by IBM Blumix WATSON.

1) It plays videos in sign language, activated by $Q R$ codes loaded in the database to show relevant information:

Videos reproduced describe a process, instructions or relevant information from government agencies, hotels, restaurants, and they are unique. This service is for all those who request or agree to place a QR code in their establishments or offices. Your video is recorded by certified interpreters and is provided free of charge. The video is uploaded to the system database, so a QR code will be sent by mail so that your users can display the video in SL.

This service requires data, to enable access to the database and streaming access to the videos. This service is free for the application users.

2) Basic dictionary of sign language:

Through a printable format on the official page, the user can download a series of words that act as activation codes to access the content of each of these words; the user, when one of these words approaches the camera of his cell phone or tablet, can observe an image that clicks on a visual and auditory action, followed by a video that explains what the sign is in SL.

3) Configuration specifications:

Users can register and generate a password to access the applications, if they wish to acquire some of the packages proposed in the character acquisition plan (for the function Text to Speech and Voice to Text). Users can change the language of the voice to text / text to voice application from Spanish to English, but all other functions remain in Spanish. Users can change to AR lenses mode. This allows you to split the screen to use this option.

\section{Prototype}

The prototype of the interface is designed following the standards for IOS applications, taking into account the responsive design and colors. Icons are designed 
considering two aspects: 1 . The meaning of the application 2 . The consideration of the target audience, since, according to Fajardo [14], icons can represent certain actions reflected in figures, since it is likely that one icon is easier for deaf people to understand than the other. That is, the icons are created from real elements, which are part of the culture of the selected users. This can improve the construction of icons that communicate what is intended: a good visualization of information to obtain a correct mental model.

According to Sánchez [15] the heuristics evaluation is an ideal evaluation method in the development of tools for people with disabilities as the usability is given by inspection, created by the expert judges from a previous principals established.

\subsection{Limitations}

The future limitations that can be presented when accessing, proving, using and validating the adapted tools, these are linked to three factors: the first one is the language for which it was built, second will be the availability from the developer to share it, it could be under development or the Project was dropped, third in case the usage of SL there is a risk that just is functional for the country that it was developed because the SL is different in every region. In addition, the majority of technologies developed do not seek the creation of models that can be replicated, since they were designed solely as a business or in some case were only in research prototypes and is not considered to hearing people as an important factor in the teaching/learning of the LS to make them partakers of the deaf culture.

On the other hand, the autonomy of the cellphone batteries play an important role in the augmented reality applications as the usage of the camera demands a high battery consumption, although this is an external problem from the application, this is a limitation of the battery type that we currently have today.

\section{$6 \quad$ APP Usage Results}

In the usability testing (in the first version), two focal groups were established where a qualitative semi-structure interview is performed with an inductive focus, in the first one the listener people isolated from any noise to interpret with the application what they were talking about, the second group of seven deaf people that had to interpret with sign language what they spoke about and written in text by the app.

The translation in real time is functional in a $65 \%$ in the Spanish language and 85 $\%$ in the English language (This is because of the characteristics of the Watson service), data that is extract from the lecture of a key text in the screen is display the probability that the phrase get close to the exact translation (This value is given by the IBM Watson service), this allows the user know if the translation was done in the correct way. Below is a table showing the main problems and advantages found in the tests: 
Table 4. The codes that were more saturated in the interviews.

\begin{tabular}{|c|c|c|}
\hline Control Group & Advantages & Disadvantages \\
\hline Listener People & $\begin{array}{l}\text { Fluent when reading and gets } \\
\text { more accurate when describing } \\
\text { the content of the test dictated } \\
\text { and translated to text in the app. }\end{array}$ & $\begin{array}{l}\text { The majority of them mentioned } \\
\text { that they could not put attention } \\
\text { in the text and the person at the } \\
\text { same time. When using the } \\
\text { augment reality glasses they fill } \\
\text { dizziness in some occasions. }\end{array}$ \\
\hline Deaf People & $\begin{array}{l}\text { They could visualize the text and } \\
\text { the person at the same time, this } \\
\text { is an important factor in the } \\
\text { communication for deaf people; } \\
\text { they considered it as a good } \\
\text { complementary tool see his/her } \\
\text { interpreter and the text to fully } \\
\text { understand the Spanish language } \\
\text { and found the app very useful. }\end{array}$ & $\begin{array}{l}\text { The velocity of reading is not the } \\
\text { same as a listener person, in some } \\
\text { cases the meaning of the word } \\
\text { was unknown to describe it in the } \\
\text { sign language, the wrong words } \\
\text { transcribed by the app change the } \\
\text { meaning of the context in some } \\
\text { cases. }\end{array}$ \\
\hline
\end{tabular}

During some testing, a test was done in Xcode for IOS operation system, using a cellphone with Chip A9 with 64 bits of Architecture, rechargeable lithium-ion battery, this test shows that $79 \%$ of the resources are required of processing of this equipment when using the service voice to text, vuforia and the camera activation, refer to Figure 5 below. A problem origin with the battery performance, because of the camera usage and also with the continues data that is being sent and received, this application demands a high impact in the energy consumption of the equipment.

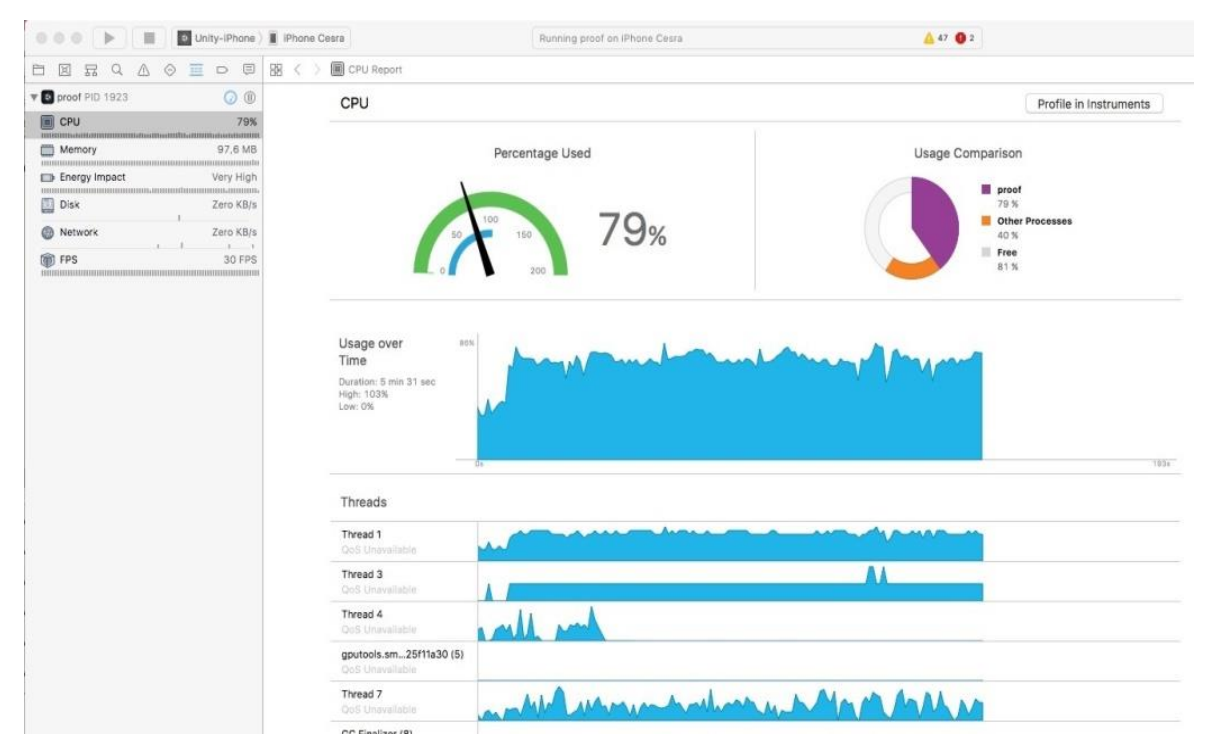

Fig. 4. CPU Test in XCODE when running the application. 


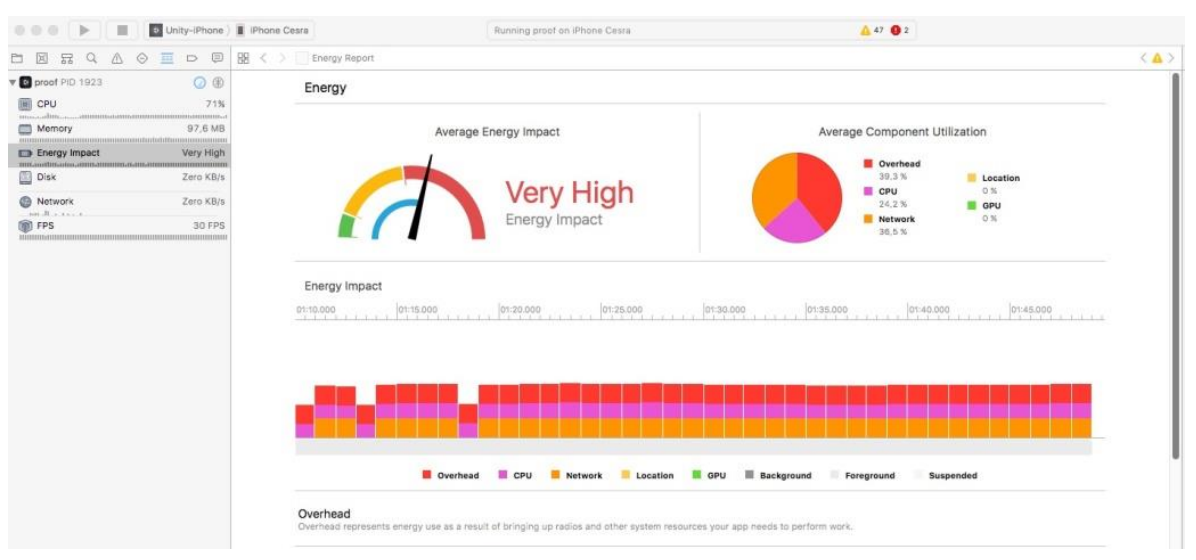

Fig. 5. Battery test performance in XCODE when running the application.

\section{Conclusion}

In some cases universities had adopted a process of inclusion in their deaf students with support of sig language interpreters, technologies of communication, and others that are not contemplated or the budget is limited this is a problem of inclusion because it is supposed in smart cities every person can have access to the technological resources available to improve the communication, regardless of the condition of each person; however, this access currently today is limited to deaf people, because there is not sufficient technology that allows the simultaneous translation from voice to text or in signs language, the lack of services that get into interactive menus or interpreter, one of the circumstance is because of the lack of implementation and develop of technologies; achieve the accessibility in different environments without depending of an interpreter of SL will benefit all users and people that interact with services in the counter, schools, hotels, etc.

This revision shows the progress for the inclusion of deaf people has been slow but shows a favorable way, the new technologies provide a better outlook for future development, it is worth mentioning that in all moments that resources must be designed to incorporate the multiple visual strategies base on research and must be educational and with the best quality to obtain a positive impact in children. Golos \& Moses [16]. Which takes us to question what it was questioned in the begging?

According to with was mentioned previously and from the point of view socio anthropological, it is important to understand the proper situations of the deaf community, recognized as a linguistic minority, the signs language user.

Therefore, development of tools for smart cities should be first priority, to respond to these needs of communication, the usage and interpretation of the information through the different methods and also usage of graphic information, rich in visual level, spatial and temporal, allowing the deaf person uses his/her cognitive domains to access the information and help in his/her learning process Rincón [17]. 
However, none of the studies found mention the importance of hearing people taking an open stance to learn sign language and access to deaf culture, in terms of a basic knowledge of SL to guarantee a society more inclusive.

At the same time investigate about the usage of technologies for the teaching / learning of Sign Language, re-define the way in which the reading and writing is transmitted to deaf people it turns in an area of opportunity to generate technological resources that warranty the access to information, education and better job positions for people with disabilities.

\section{$8 \quad$ Future Work}

The augmented reality, the virtual reality and the engines of voice recognition, currently are part of the new systems of accessing the information for education, geolocation, training, customer support or of amusement; provide a society alternatives to access the contents in an interactive way and experiential, improving with this the experience of learning, buying, managing, interact with virtual objects, and so much more applications, usage that can be also well use in the inclusion environment; to provide an alternative in the usage of technological tools like a support for deaf people inside the society, since it is possible to observe the interlocutor, an important factor in communication as human-to-human communication consists of words, non-verbal linguistic modifiers (paralanguage), and visual cues or gestures.

The growth in the research in this nature analyzed in this systematic revision are showing a positive trend to the augmented reality, virtual reality and the inclusion of people with any disability in the Smart cities.

Base on the systematic revision shown and the analysis of the existing technology (Looking for the optimization of it), undertakes from the Smart Cities Innovation Center at the University of Guadalajara the Project: "Technological-Social Model. Based in augment reality platforms for the inclusion of deaf people in the university class-room and the cities." like a proposal for the innovation in the Smart Cities in social inclusion matter. In which has two main research:

1. Testing usability in an application developed with augment reality, translation from voice to text (using a sound filter since the recognition rate of a speech or speaker recognition system can decline to a lot by the influence of noise [18]) and incorporate videos activated with codes QR in SL as a means of access to information. (used Linguistic Knowledge for Machine Translation Evaluation as proposed by Samiksha [19]).

2. Explore the implementation of a contextualized off-line search engine that allows the users to continue using the application [20].

3. Measure the social impact of the Usage of serious game developed for the teaching of SL using user interfaces of gesture recognition and voice commands, As a means of access to the learning of basic SL. 
4. Testing usability in an application developed with augment reality for the teaching of SL which displays objects associated with its meaning in Spanish (the word) and their sign language.

With the usage of augment reality to improve the level of visual communication allowing the users to access the gesture communication of its interlocutor, for instance, in the case of a classroom even if the teacher is writing when he is standing with the back turned the user will be receiving the translation and also see what the professor is saying, although this application can be used in any context of the city.

Searching that this technology be validated by the user; Because of this reason, statistics will be taken to analyze the percentage of translation errors, estimated time of usage, how easy is for the user create an activity, how fast can get used to its usage, how pleasant is using the interface (learning, efficiency, memorability, task error, satisfaction) and its utility (if the interface performs what is needed from the user) the objective is to analyze if the VR and the simultaneous translation allows the end user has access the information in an effective way.

Furthermore, take advantage of the technologies of virtual interfaces like Kinect (adapting the model of Speech to sign language of Caballero [21]) to create a serious game for the teaching/learning of SL and promote an inclusive social environment This can be used by people to learn basic signs, which may put in practice in front of a Kinect (as a way of validating if the sign that is being learned corresponds to the correct way to play it, analyzing regular correspondences between related languages [22]).

The serious game will be shared at the Language Center of the University Center of Administrative Economic Sciences of the University of Guadalajara and in some public transport of the city of Guadalajara (those with screens, in the area of operations of Digital Creative City), with the intention to measure the time that the user learns a sign and the interest in learning SL in a playful way by members of the society.

The model becomes important when trying to create a tripartite link between technology-society-institutional strategy, since it not only seeks to provide technology to people with disabilities but to consent to the society of the importance of the learning of SL to provide inclusive spaces; as well as the analysis of the institutional strategies that receive the deaf community to be replicated. Since the opportunity that provides access to the information opens the possibility of adding to the labor force to this social group, a force that has been wasted; for example, in Mexico, according to re-ports of the INEGI, $70 \%$ of the Mexican population with disabilities is economically inactive, The search for a replicable model also opens doors to provide opportunity to access an educational environment, without leaving behind the importance of having a sign language interpreter, but with technology, the user does always need to depend on him/her interpreter at all times (for the lack of certified interpreters in the institutions). 


\section{References}

1. Bouzid, M.A., Khenissi, F., Essalmi, M., et al.: Using Educational Games for Sign Language Learning - A Sign Writing Learning Game: Case Study Learning Game. Educ. Technol. Soc., 19(1), pp. 129-141 (2016)

2. Ruiz, A.L.: ¿Educación inclusiva? Análisis del marco jurídico sobre el derecho de acceso y permanencia en la educación superior para las personas Sordas en la ciudad de Bogotá. Incl. Educ. Anal. Leg. Framew, 33, pp. 1-55 (2016)

3. Baker, P.M., Bellordre, C.: Adoption of information and communication technologies: key policy issues, barriers and opportunities for people with disabilities. System Sciences, Proceedings of the 37th Annual Hawaii International Conference on IEEE (2004)

4. OMS: http://www.who.int/disabilities/world_report/2017/es/index. html (2017)

5. Kitchenham, B., Charters, S.: Guidelines for Performing Systematic Literature Reviews in Software Engineering. Keele University and Durham University Joint Report (2007)

6. Shepperd, S.G., MacDonell, M.J.: Comparing Local and Global Software Effort Estimation Models Reflections on a Systematic Review. Empirical Software Engineering and Measurement (2007)

7. Dilo con señas: http://www.diloensenas.com/inicio (2016)

8. Greene, J.R., et al.: Electronic translator for assisting communications (2002)

9. Chen, X., Li, H., Pan, T., Tansley, S., Zhou, M.: Kinect Sign Language Translator expands communication possibilities (2013)

10. Hand Talk: Digital translation for Brazilian Sign Language. https://handtalk.me/ (2012)

11. AVA: https://www.ava.me/ (2017)

12. Mirzaei, M.R., Mortazavi, M. et al.: Combining augmented reality and speech technologies to help deaf and hard of hearing people. Virtual Augment. Reality, pp. 174181 (2013)

13. Nagori, N.P., Malode, V.: Communication Interface for Deaf-Mute People using Microsoft Kinect, Int. Conf. Autom. Control Dyn. Optim. Tech., pp. 640-644 (2016)

14. Fajardo, I., Abascal, J., Cañas, J.J.: Bridging the digital divide for deaf signer users. In: 15th European Conference on Cognitive Ergonomics: The Ergonomics of Cool Interaction, ECCE, pp. 1-37, ACM (2008)

15. Sánchez, J., Zapata, M., Jiménez, J.: Evaluación heurística de la usabilidad de software para facilitar el uso del computador a personas en situación de discapacidad motriz. Revista EIA (2017)

16. Golos, D.B., Moses, A.M.: Supplementing an Educational Video Series with Video (2015)

17. Rincón, M. L.: ¿Cómo la comprensión de lectura en estudiantes sordos se ve facilitada por el uso de tecnologías de la comunicación e información?, Rev. la Fac. Med., 63(3) Sup, pp. 83-91 (2008)

18. Lai, W.H., Yang, C.J., Wang, S.L.: Post-Processing for the Mask of Computational Auditory Scene Analysis in Monaural Speech Segregation. Computación y Sistemas, 21(4) doi: 10.13053 (2017)

19. Tripathi, S., Vineet, K.: Using Linguistic Knowledge for Machine Translation Evaluation with Hindi as a Target Language. Computación y Sistemas, 21(4) (2017)

20. Centelles, J., Costa-Jussà, M.R., Banchs, R.E., Gelbukh, A.: On-line and Off-line ChinesePortuguese Translation Service for Mobile Applications. Computación y Sistemas, 18(3), pp. 603-610. DOI: 10.13053/CyS-18-3-2047 (2014) 
César Lozano Diaz, Rocio Maciel M., Manuel Larios V., C. Alberto Ochoa

21. Caballero, S.O., Trujillo, F.: 3D Modeling of the Mexican Sign Language for a Speech-toSign Language System. Computación y Sistemas, 17(4). DOI: 10.13053/CyS-17-4-2013011(2013)

22. Fischer, A.K., Vreeken, J., Klakow, D.: Beyond Pairwise Similarity: Quantifying and Characterizing Linguistic Similarity between Groups of Languages by MDL. Computación y Sistemas, 21(4) (2017) 